\title{
Reassessing the Trade-off Hypothesis How Misery Drives the Corruption Effect on Presidential Approval
}

Rosas, Guillermo; Manzetti, Luigi

Document Version

Accepted author manuscript

Published in:

Electoral Studies

DOI:

10.1016/j.electstud.2015.03.002

Publication date:

2015

License

CC BY-NC-ND

Citation for published version (APA):

Rosas, G., \& Manzetti, L. (2015). Reassessing the Trade-off Hypothesis: How Misery Drives the Corruption Effect on Presidential Approval. Electoral Studies, 39, 26-38. https://doi.org/10.1016/j.electstud.2015.03.002

Link to publication in CBS Research Portal

\section{General rights}

Copyright and moral rights for the publications made accessible in the public portal are retained by the authors and/or other copyright owners and it is a condition of accessing publications that users recognise and abide by the legal requirements associated with these rights.

Take down policy

If you believe that this document breaches copyright please contact us (research.lib@cbs.dk) providing details, and we will remove access to the work immediately and investigate your claim. 


\section{Reassessing the Trade-off Hypothesis: How Misery Drives the Corruption Effect on Presidential Approval}

Guillermo Rosas and Luigi Manzetti

Journal article (Accepted version)

CITE: Reassessing the Trade-off Hypothesis : How Misery Drives the Corruption

Effect on Presidential Approval. / Rosas, Guillermo; Manzetti, Luigi. In: Electoral

Studies, Vol. 39, 09.2015, p. 26-38.

DOI: 10.1016/j.electstud.2015.03.002

Uploaded to Research@CBS: July २०17

(C) 2017. This manuscript version is made available under the CC-BY-NC-ND 4.0 license

http://creativecommons.org/licenses/by-nc-nd/4.0/ 


\section{Accepted Manuscript}

Reassessing the Trade-off Hypothesis: How Misery Drives the Corruption Effect on Presidential Approval

Guillermo Rosas, Luigi Manzetti

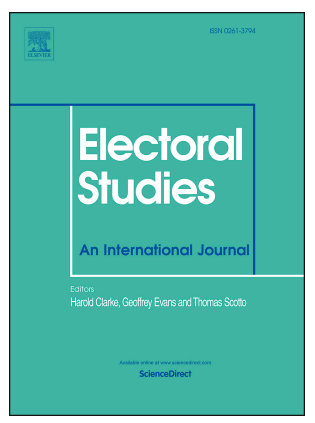

PII: S0261-3794(15)00047-5

DOI: 10.1016/j.electstud.2015.03.002

Reference: JELS 1561

To appear in: Electoral Studies

Received Date: 29 April 2014

Revised Date: 6 October 2014

Accepted Date: 2 March 2015

Please cite this article as: Rosas, G., Manzetti, L., Reassessing the Trade-off Hypothesis: How Misery Drives the Corruption Effect on Presidential Approval, Electoral Studies (2015), doi: 10.1016/ j.electstud.2015.03.002.

This is a PDF file of an unedited manuscript that has been accepted for publication. As a service to our customers we are providing this early version of the manuscript. The manuscript will undergo copyediting, typesetting, and review of the resulting proof before it is published in its final form. Please note that during the production process errors may be discovered which could affect the content, and all legal disclaimers that apply to the journal pertain. 


\section{Reassessing the Trade-off Hypothesis: How Inflation Drives the Corruption Effect on Presidential Approval}

\author{
Guillermo Rosas* \\ Department of Political Science \\ Washington University in St. Louis \\ One Brookings Drive \\ St. Louis, MO 63130 \\ grosas@wustl.edu
}

Luigi Manzetti

Department of Political Science

Southern Methodist University

PO Box 750235

Dallas, TX 75275

lmanzett@mail.smu.edu

${ }^{*}$ Corresponding author 


\section{Reassessing the Trade-off Hypothesis: How Misery Drives the Corruption Effect on Presidential Approval}

A vast number of economic and political analyses since the 1990s conclude that corruption is a serious impediment to growth (Ades and Di Tella, 1999; Mauro, 1995). The persistence of corruption in young democracies not only hampers their economic potential, but it undermines trust in government and delegitimizes the very institutions that should uphold the rule of law (Anderson and Tverdova, 2003; Chang and Chu, 2006; Della Porta, 2000; Seligson, 2002). Moreover, corruption increases political alienation and discourages political participation, creating a fertile ground for populist candidates who further weaken checks and balances to consolidate their hold on power (Davis, 2004; McCann and Domínguez, 1998).

Yet, corruption has not only persisted and taken new forms, but politicians with a tarnished reputation have been elected, and even re-elected, at the highest levels of government in several countries. To add insult to injury, democratically-elected politicians who have championed reforms with the goal of limiting opportunities for corruption often manipulated these reforms for personal gain. Some of the most notorious cases have happened in Latin America, the region that we investigate. For example, Carlos Menem (1989-99) was re-elected to a second term in Argentina on a record of strong economic performance despite widespread allegations of corruption involving him and high profile members of his administration. Much the same can be said about Brazilian President Luiz Inácio Lula da Silva (2003-2010), who presided over a period of unprecedented prosperity and won re-election despite a rash of scandals which forced out some of his closest cabinet members.

Why do people support leaders that condone corruption? A recent media report on Argentina expresses a widely-held view: "Social research confirms that there seems to be an 'implicit contract' of the Argentine people with their leaders which metaphorically says something like this: you 
give us jobs and consumption, and we tolerate your 'dirty' deals, but if benefits cease we will listen to those who expose you". ${ }^{2}$ Indeed, research in the social sciences speaks of a "trade-off" hypothesis according to which citizens might fail to hold governments accountable for corruption when economic outcomes are positive (Kurer, 1993; Pereira, Melo and Figueiredo, 2009; Rundquist, Strom and Peters, 1977).

We argue that inflation and unemployment, rather than poor economic growth, make citizens wary of their government's inability to curtail corruption. That is, we at best expect corruption to drive down government approval in contexts of high inflation and unemployment. In a nutshell, our expectation follows from knowledge that inflation affects everyone, whereas growth may have a varied impact on different social strata. We also make an important methodological contribution. Previous work relies on respondents' perceptions of corruption as predictors of vote choice or government approval rather than on actual participation in corrupt acts. Such studies hold perceptions to be genuine assessments of corruption, without grappling seriously with the notion that perceptions may be tainted by partisan affiliation or sympathy for the government; in fact, corruption perceptions may be endogenous to the very outcomes, like presidential approval, they purport to explain. To overcome this problem we use corruption victimization measures which minimize endogeneity bias produced by perception measurements (Gingerich, 2009; Seligson, 2002, 2006).

We base our analysis on 80+ surveys from the Latin American Public Opinion Project, which provide consistently-worded questions over several years in most Latin American countries. Focusing on countries with a shared history and similar developmental experiences yields unquestionable advantages. Specifically, the understanding of what corruption means is likely to be more similar in places like Peru or the Dominican Republic than in, say, Finland or Taiwan. Similarly, the fact that all Latin American countries in our sample are presidential regimes reduces the possibility of confounding because of extreme variations in "clarity of responsibility" for corruption (Powell and Whitten, 1993; Tavits, 2007), which would be more worrisome if our sample were to include parliamentary regimes.

The results are largely consistent with our hypotheses, but with a remarkable accent that makes

\footnotetext{
1 "Does Cristina Fernández have time to combat the scourges of insecurity and inflation?", Merco Press, Monday, September 9, 2013.
} 
us less pessimistic about the prospects of holding politicians accountable for corruption. Across a variety of economic situations - from high to low growth, from full employment to massive unemployment, and from stable to inflationary environments - citizens who experience corruption tend to disapprove of their president's performance. Contrary to a strong version of the trade-off hypothesis, victims of corruption give presidents low marks even under conditions of macroeconomic stability, high employment, and good economic growth. However, we uncover some evidence consistent with a weaker version of the trade-off hypothesis: Though citizens that experience corruption tend to chastise their presidents, they are much more likely to do so in situations of high inflation and unemployment. Monetary instability and lack of employment opportunities, but not dismal economic growth, are the catalyzers that turn citizens' experiences of corruption into low rates of presidential approval.

We develop our argument as follows. Section 1 frames our expectations regarding the conditional effect of corruption victimization on presidential approval within established research programs. Section 2 introduces the data on which we base our claims. We develop a multilevel model of presidential approval that accounts for the characteristics of our data in Section 3, and in Section 4 we discuss our main findings. We conclude in Section 5 that Latin American respondents are more sophisticated, demanding, and willing to hold presidents accountable for corruption than previously thought.

\section{Why would economic outcomes drive variation in the corruption effect?}

According to the trade-off hypothesis, individuals that perceive and/or suffer corruption do not allow these perceptions and experiences to inform their attitudes toward incumbents, including levels of presidential approval, which is the outcome we inspect. When they do, we refer to the existence of a "corruption effect." Our goal in this paper is to evaluate whether economic outcomesinflation, unemployment, growth - have an impact on the corruption effect. This requires that we first summarize existing knowledge about the effect of corruption, on the one hand, and of economic outcomes, on the other, on approval. Only then will we consider why the corruption effect might itself be affected by economic outcomes.

Academic analyses that address the puzzle of citizen support for corrupt politicians are a recent 
phenomenon. A few studies have tried to identify potential rationales behind this behavior. Two of the most important rationales concern information - voters continue to support corrupt politicians because they are ignorant of their corruption proclivities - and material gain - voters obtain tangible policy benefits from incumbents and are willing to overlook their corruption proclivities, even when these are known (Kurer, 2001; Golden, 2009). A number of empirical analyses of corruption build on the information rationale. Looking at Brazil, for example, Pereira, Melo and Figueiredo (2009) find that federal congressmen facing corruption charges are less likely to run for re-election, whereas Ferraz and Finan (2008) discover that voters penalize incumbents when judicial investigations and audit reports uncover corruption, particularly in electoral years. Two further case studies in Italy (Chang, Golden and Hill, 2010) and Brazil (Winters and Weitz-Shapiro, 2013) using different methodologies and research designs indicate that the availability of reliable information plays a pivotal role in punishing corrupt incumbents.

Another stream of academic works on corruption stays close to the notion of policy benefits. These contributions theorize that citizens decide whether or not to support an incumbent politician based upon the performance of the economy or upon receiving material incentives; in other words, these studies consider the possibility that economic outcomes affect government approval. ${ }^{2}$ Available evidence, particularly in advanced democracies, certainly shows that governments are more likely to be re-elected during good economic times while they are more likely to suffer electoral defeats in economic downturns (Kayser, 2009; Kayser and Wlezien, 2011; Kinder and Kiewiet, 1981; Lewis-Beck, 1988). When it comes to the role of economic conditions and corruption assessments in understanding incumbent support, Stokes (2001) explains the impeachment of Venezuelan President Carlos Andrés Pérez (1989-1993) on embezzlement charges by emphasizing his inability to turn around the economy. On the contrary, Presidents Carlos Menem (1989-1999) in Argentina and Alberto Fujimori (1990-2000) in Peru enjoyed considerable popular support for most of their tenure despite mounting corruption allegations precisely because they succeeded most of all in ending hyper-inflation, which had devastated both countries by the late 1980s.

At the cross-national level, Choi and Woo's (2010) analysis of 115 developing countries also

\footnotetext{
${ }^{2}$ Along the rationale of support in exchange for direct material benefit, Winters and Weitz-Shapiro (2013) find no evidence for a version of the trade-off hypothesis in which voters are expected to support corrupt politicians as long as they benefit from private side-payments.
} 
shows that corruption becomes an important and negative factor when the incumbent governments are held responsible for poor economic performance. In a recent study covering a cross-section of nineteen Latin American countries, Zechmeister and Zizumbo-Colunga (2013) find that economic conditions mediate the effect of corruption perceptions on presidential approval. Their work uncovers evidence that, at the individual level, presidential approval ratings are strongly affected by the interaction between subnational economic conditions and perceived levels of corruption. As a result, good economic conditions - proxied by the proportion of respondents within subnational administrative units that report recent losses in household income - tend to make individuals more tolerant of corruption, while bad economic conditions magnify the negative impact of corruption perceptions. This finding is consistent with the trade-off logic, but its reliance on self-reported measures of economic improvement aggregated at the subnational/regional level and on corruption perceptions tends to exaggerate the magnitude of the trade-off effect.

The importance of presidential approval ratings as a measure of citizen control is similarly well established in the literature. As Carlin, Love and Martínez-Gallardo (forthcoming) note, presidential approval ratings serve as a form of executive accountability in off election years not only in the United States (Gronke and Newman, 2003), but also in Latin America. In fact, there is enough evidence to suggest that presidents across the region are sensitive to public opinion shifts since sustained negative trends may bolster congressional opposition and defections within their governing coalitions (Calvo, 2007). Moreover, ignoring approval rates may result in street riots that force abrupt resignations from office, as has happened in Argentina, Brazil, and Ecuador (Pérez Liñán, 2007). There is also substantial evidence demonstrating the relationship between corruption and presidential approval ratings. A number of studies find that corruption negatively affects people's evaluation of both political institutions and incumbent presidents (Canache and Allison, 2005; Hochstetler, 2006; Pérez Liñán, 2007).

Finally, the literature has documented over the past two decades an impact of inflation, unemployment, and even economic growth on approval ratings and electoral outcomes, although there is no consensus on which of these variables is most important (Lewis-Beck and Stegmaier, 2008; Carlsen, 2000). Just looking at Latin America, Johnson and Ryu (2010) report that inflation, but not growth, has a negative effect on presidential approval in Central America. Echegaray (2005) comes to similar conclusions for Latin American elections as a whole, whereas Remmer (2003) 
concludes that inflation and growth have a similar impact on electoral outcomes. At the opposite side of the spectrum, Singer (2013) argues that, on balance, growth is paramount in shaping electoral support over the long haul. In spite of these conflicting results, we do know that Latin Americans hold their politicians accountable for the state of the economy (Gelineau, 2007) and presidential approval ratings are particularly dependent on it (Carlin, Love and Martínez-Gallardo, forthcoming).

We know, then, that macroeconomic outcomes affect presidential approval, and that a corruption effect also exists on presidential approval. We want to know, however, whether the corruption effect on presidential approval varies in magnitude depending on economic conditions. We expect inflation and unemployment to have a greater impact than economic growth on the size of the corruption effect. To rationalize this expectation, consider the original justification behind Arthur Okun's celebrated misery index (misery $=$ inflation rate + unemployment rate). The logic behind this index is that inflation and unemployment are more accurate gauges of the impact of bad economic conditions on the purchasing power of an average citizen. Inflation is a tax that affects all citizens; more specifically, situations of high inflation are extremely disruptive, and ordinary citizens have little capacity to protect themselves from its worst effects. By the same token, high unemployment rates suggest that labor markets may be extremely tight, so that even those lucky enough to be employed cannot easily search for better-paid jobs. The primacy of inflation and unemployment as potential drivers of the corruption effect is also well documented in Powell and Whitten's (1993) clarity of responsibility thesis according to which citizens perceive both factors to be under the control of the incumbent government.

Conversely, the effect of economic growth in shaping people's evaluations is not straightforward in an environment of capital mobility and trade openness. In the specific context of contemporary Latin America, economic growth in many countries has recently been driven, as it was a century ago, by a new boom in the export of commodities, which remains a trade shaped largely by external conditions and well beyond government manipulations. Following this logic, some scholars have argued that citizens are less likely to hold incumbents responsible for economic growth as economies have become more interdependent due to globalization (Hellwig and Samuels, 2007). We suggest that as globalization decouples economic growth from economic voting considerations, it also diminishes the impact of economic growth on the corruption effect. We test in Section 3 the 
proposition that inflation and unemployment, more so than economic growth, drives the corruption effect in Latin America.

\section{Presidential approval, corruption victimization, and economic outcomes}

We base our analysis on information from 141,000+ respondents in eighty-three nationally representative AmericasBarometer surveys fielded in eighteen Latin American countries between 2004 and 2012, thus including between three and six available survey rounds for each country. ${ }^{3}$ The outcome, presidential approval, is an ordered categorical variable that captures respondents' assessments of the country's current president on a five-point scale, from "very bad" to "very good"; in all cases, the survey question identifies the current president by name. ${ }^{4}$ The distributions of responses across surveys are quite varied, though in general they are all unimodal, and in most cases the modal qualification of the president's job is "average." 5

The main individual-level predictor in our analysis is corruption victimization. As we noted before, scholarly work typically employs questions on perceptions, rather than victimization, to

\footnotetext{
${ }^{3}$ The countries we consider are Argentina, Bolivia, Brazil, Chile, Colombia, Costa Rica, Dominican Republic, Ecuador, El Salvador, Guatemala, Honduras, Mexico, Nicaragua, Panama, Paraguay, Peru, Uruguay, and Venezuela. Eighty-seven surveys are available to the public, and in parts of our analysis we include them all; however, we dropped Brazil 2006, Ecuador 2004, Guatemala 2004, and Mexico 2004 from our main analysis because these surveys lacked several crucial questions.

${ }^{4}$ Item M1 reads: "Speaking in general of the current administration, how would you rate the job performance of President NAME CURRENT PRESIDENT?" Thus, respondents know which president they ought to assess even where presidential elections may have occurred recently. Naturally, the surveys were collected at various times with respect to a country's presidential election calendar, which means that some respondents have had a longer time to form an opinion of the sitting president. We do not expect these varying "lead" times to systematically correlate with the economic variables whose impact we want to assess (presidential elections are, after all, exogenously timed), but they may well affect respondents' propensities to approve of the president, which is why we include random cutpoints in our models. In two surveys - the 2010 rounds in Chile and Uruguay - an additional item (M1a) includes an approval question for outgoing Presidents Bachelet and Vazquez, and in Costa Rica 2006 M1 explicitly refers to "the past government of President Pacheco." To ensure consistency, we use M1 as the outcome variable across all surveys.
}

${ }^{5}$ An online appendix contains question wording, summary statistics, rates of missingness for all indicators, and a host of complementary analyses. 
Figure 1: Rates of bureaucratic corruption victimization as a predictor of Transparency International's corruption perceptions index scores in 83 LAPOP surveys

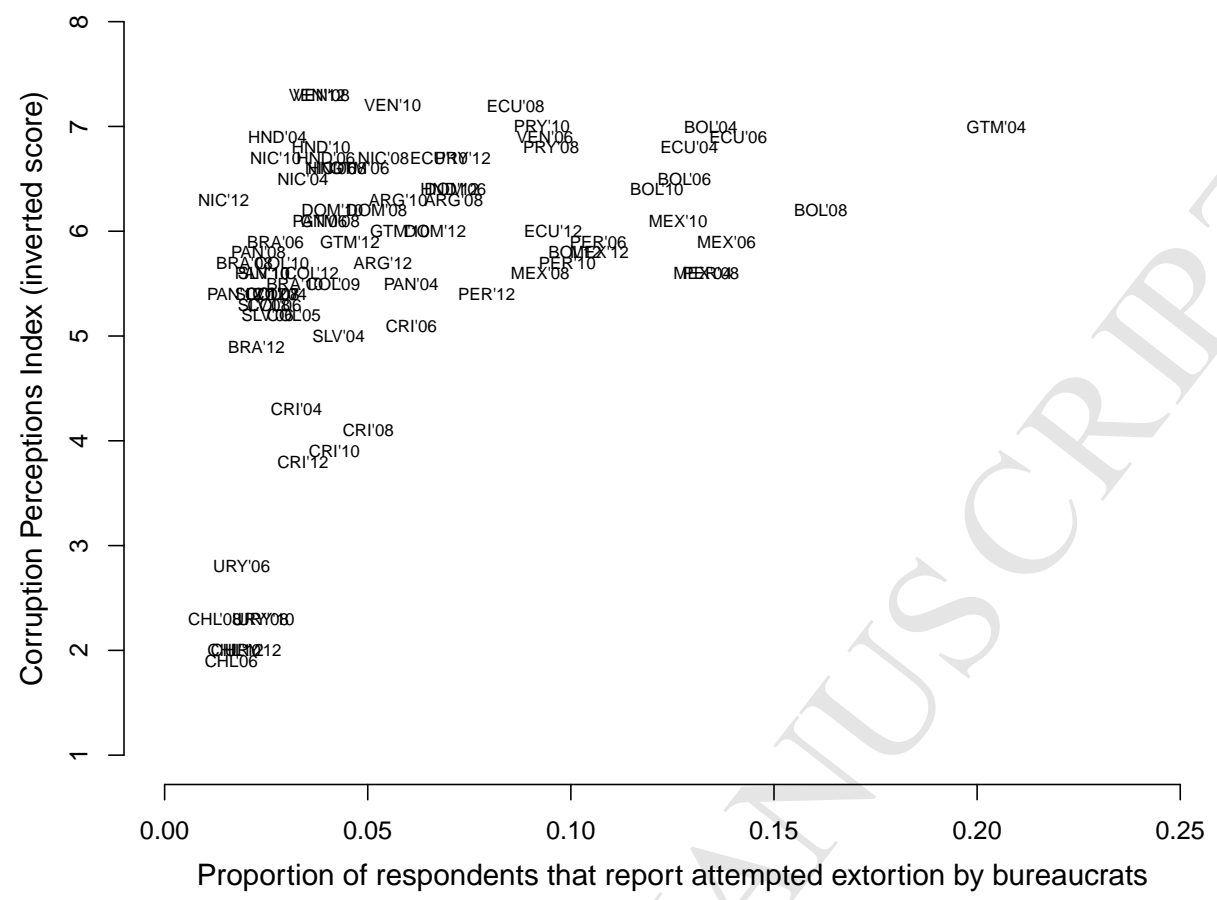

gauge the incidence of corruption in a country. In fact, the surveys we use include a question that asks respondents whether they perceive corruption among public officials to be common (item EXC7). We do not find much fault with perception measures when they are aggregated at the country level, as in fact country-level measures of corruption tend to show strong correlations across different datasets. However, considering corruption perceptions as a predictor of presidential approval at the individual level is problematic, since respondents are likely to develop and/or rationalize both attitudes simultaneously. In other words, there is a risk of tautology in that individuals may disapprove of their government because they perceive corruption, but declare high perceptions of corruption because they disapprove of their government. This endogeneity bias might yield grossly exaggerated estimates of the effect of corruption. ${ }^{6}$

\footnotetext{
${ }^{6}$ We have in fact estimated a variety of models using the indicator of corruption perceptions instead of corruption victimization; invariably, estimated effects are much larger when we use corruption perceptions, which is consistent with our speculation that perception reports are at least partly driven by presidential approval. For a review of the literature on the endogenity issue, particularly focusing on economic perceptions, see Kayser and Wlezien (2011). On endogeneity and measures of corruption perceptions see Seligson (2006). Evidence of endogeneity, on the one hand, obtains from the fact that corruption perceptions tend to correlate with perceptions about government performance
} 
To lessen this concern, we inspected a variety of corruption victimization items in the AmericasBarometer surveys. Seligson (2006) grounds the use of corruption victimization on the sociological literature on crime victimization and argues that corruption victimization items are less likely to suffer from these obvious endogeneity concerns, while simultaneously recognizing that such concerns cannot be entirely eliminated. ${ }^{7}$ Several survey questions elicit reports on bribe solicitation in exchange for services offered by municipalities, public hospitals, and court systems, but many of these questions are asked inconsistently throughout surveys or inquire about very specific behaviors that respondents may or may not tie to presidential competence. ${ }^{8}$ We thus limited our inquiry to one item that questions whether public employees (empleados públicos) have attempted to extort a bribe from the respondent (EXC6). ${ }^{9}$ We call this bureaucratic corruption and use it as an indicator of victimization because this is a behavior that respondents are likely to trace back to high echelons of government. The bureaucratic corruption indicator has prima facie validity as a measure of the incidence of corruption. To see this, we plot Transparency International's Corruption Perceptions Index against the percentage of respondents in each survey that report extortion attempts by bureaucrats in Figure $1 .^{10}$ There is a positive correlation between rates of bureauon human rights, inflation, jobs, or access to public services (Abramo 2008, Rose and Mishler 2007, Klaŝnja, Tucker and Deegan-Krause 2012). On the other hand, Tverdova (2011) and Morris (2008) find that mass perceptions of corruption closely track elite evaluations of corruption, which presumably are less affected by presidential approval.

${ }^{7}$ See Klaŝnja, Tucker and Deegan-Krause (2012) and Morris (2008) for discussions on the link between corruption perceptions and victimization. We have inspected survey-specific corruption victimization rates and established that they do not vary drastically within countries (though naturally they vary a bit more in countries where the average corruption victimization rate is high), even when the individual-level effect of corruption victimization varies drastically within countries, as we show in Figure 2. Furthermore, none of the indicators of economic activity that we analyze - unemployment, inflation, growth - are statistically significant predictors of cross-survey corruption victimization, but they are good predictors of corruption perceptions. Though true exogeneity would require randomized assignment of respondents to various corruption victimization conditions, this evidence is consistent with Seligson's (2006) view that the corruption victimization items are less likely to produce inflated estimates of corruption effects.

${ }^{8}$ For example, police corruption victimization likely elicits responses about local-level police officers (Klaŝnja, Tucker and Deegan-Krause 2012, Morris 2008).

${ }^{9}$ This dummy indicator is coded 1 when the respondent reports a bribe solicitation during the twelve months prior to the interview.

${ }^{10}$ Transparency International's CPI is a measure at the country-level that aggregates information from various 
Figure 2: Unpooled and partially-pooled coefficients of corruption victimization in 83 surveys of Latin American citizens (these coefficients summarize the effect of victimization on respondents' proclivities to approve of the president). Unpooled coefficients are estimated in 83 ordered probit models of presidential approval in as many country-year surveys. Partially-pooled coefficients are from Model 3 (Table 1). All models control for respondent's vote choice in the previous election (anti-incumbent, pro-incumbent, or abstention), left-right self-placement, income, education, age, gender, and urban/rural environment.

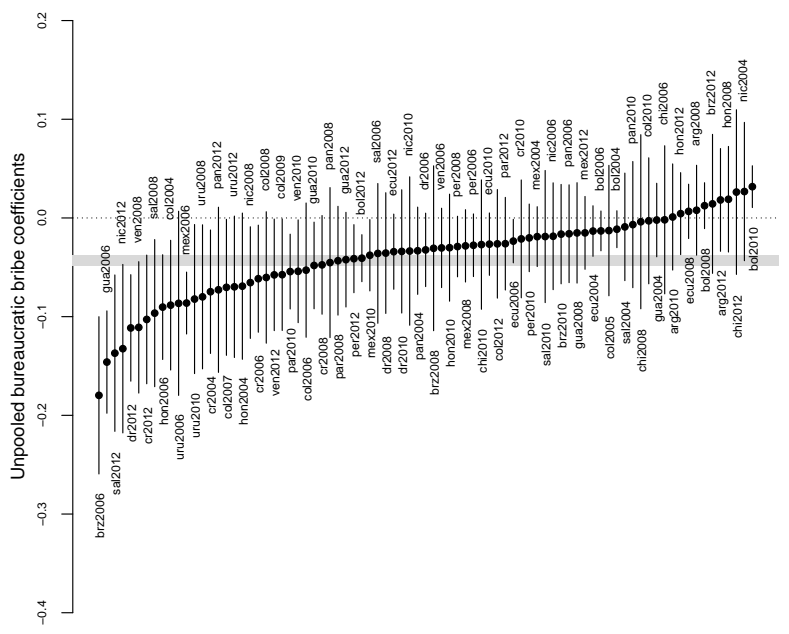

(a) Unpooled coefficients

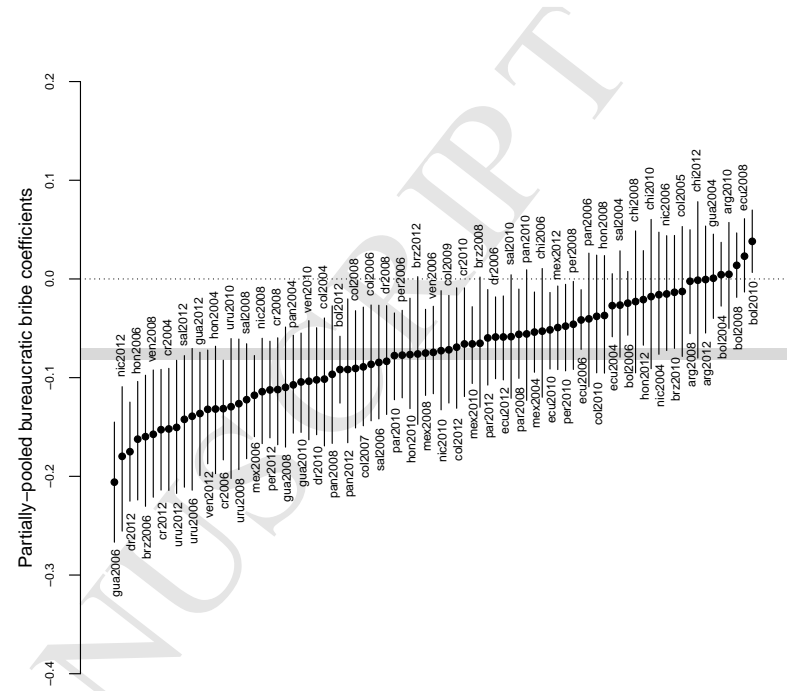

(b) Partially-pooled coefficients

cratic corruption and CPI (0.44), though there is ample variation in bureaucratic victimization among countries with high corruption scores. In our sample, the average bureaucratic corruption report rate is about $6 \%( \pm 4 \%)$, with a maximum rate of $20.5 \%$ observed in the Guatemala 2004 survey. Our task is not to determine whether victims of bureaucratic corruption disapprove of their presidents unconditionally, but how their disapproval varies under positive and negative economic conditions. $^{11}$

We control for a set of individual-level covariates that are likely to determine both corruption victimization and presidential approval. We include a standard battery of socio-economic status insurveys among experts, business organizations, and citizens.

${ }^{11}$ There might be some concern that our results rest on a relatively small number of respondents that report corruption victimization. To assuage this concern, we estimated alternative individual-level models using (i) reports of police bribe attempts, (ii) an additive index of reports of bureaucratic and police bribe attempts, and (iii) an either/or index of reports of bureaucratic and police bribe attempts (see Appendix). Especially with (ii) and (iii), the number of respondents reporting corruption more than doubles; however, estimates of the effect of corruption victimization on presidential approval remain similar across indices. Other victimization items are not always included in all LAPOP surveys, limiting our attempts to construct alternative indices. 
dicators (age, education, gender, self-reported income, urban/rural environment) based on previous findings that these might determine the chances of experiencing corruption while simultaneously driving presidential approval proclivities (Canache and Allison, 2005; Seligson, 2006; Golden, 2009). We also include items that capture the political position of the respondent vis-à-vis the government. Among the latter, we consider self-reported ideological placement on the left-right continuum and the respondent's vote in the previous election (pro-, anti-incumbent, or abstention), since we know that citizens that report voting for a losing presidential candidate are likely to express disapproval of the current government and will also be more likely to perceive widespread corruption and perhaps exaggerate the incidence of bribe solicitations (Davis, Camp and Coleman, 2004; Anderson and Tverdova, 2003). ${ }^{12}$

Before introducing our survey-level indicators and modeling strategy, we emphasize the importance of estimating the effects of corruption in a multilevel model that can cope with causal heterogeneity across countries and throughout time. Causal heterogeneity is readily apparent when we gauge the association between corruption victimization and presidential approval across surveys. Figure 2a displays unpooled estimates of the corruption victimization coefficients from ordered probit models of presidential approval based on 83 surveys in which we also control for the individual-level confounders identified above. As is obvious from this display, the effects of corruption perceptions on presidential approval vary dramatically: for example, they take large negative values in Brazil 2006 or Venezuela 2008 - suggesting that respondents that report bureaucratic bribe attempts are very likely to offer scathing appraisals of the president-but we also see null effects in about one-half of country-year datasets. The grey horizontal bar is a $95 \%$ confidence interval of the naïve complete-pooling estimate of the effect of corruption victimization on presidential approval $(-0.05 \pm 0.003)$. Because these models are based on standardized predictors, the deleterious effect on presidential approval of suffering corruption is not -0.05 , but actually larger: compared to an individual that does not suffer corruption, a corruption victim is expected to drop

\footnotetext{
${ }^{12}$ In our original specifications, we also included the respondent's opinion on the recent performance of the national economy as a predictor, based on Anderson's (2007) analysis of retrospective sociotropic appraisals of the economy. We omitted this variable because we suspect it is endogenous to approval (cf. Erikson 2004, Evans and Andersen 2006, Palmer and Duch 2001). Our results, however, do not depend on the omission or inclusion of this covariate.
} 
2 (out of 5 ) points in her approval of the president in the average survey. ${ }^{13}$ Were we to make inferences based on the complete-pooling estimate, we would likely conclude that corruption and presidential approval are inversely related everywhere. Yet, as the trade-off hypothesis suggests and Figure 2a corroborates, we neither expect nor do we witness corruption victimization driving presidential approval downward in every single country. ${ }^{14}$

We have established that the effects of corruption victimization on presidential approval vary across surveys. We now turn to whether a trade-off logic can account for this variation. To do this, we need to include indicators of economic performance-along with level of economic development and other controls - at the survey level. As indicators of economic performance we consider economic growth, inflation (log scale), and unemployment. ${ }^{15}$

Figure 3 shows the economic paths of Argentina, Mexico, Peru, and Venezuela during the period under inspection, along with the average experience of growth, employment, and inflation in the region. In general terms, the period that we inspect includes all sorts of economic experiences: from very high growth rates $(7.29 \%$ in Venezuela 2004$)$ to severe recession $(-2.68 \%$ in Mexico 2009), from extremely low rates of inflation (0.2\% in Panama 2004) to episodes of hyperinflation (51.5\% in the Dominican Republic in 2004), and from low to high unemployment $(3.9 \%$ to $18.4 \%$

\footnotetext{
${ }^{13}$ Predictors are standardized in all of our models to aid the process of estimation through maximum likelihood and MCMC later on. The coefficient estimate implies that a standard deviation change in corruption victimization is associated with a half-point decrease in presidential approval (in these models, presidential approval is not considered an ordered category, but a continuous variable with values 1, 2, 3, 4, 5; we model this outcome appropriately below).

${ }^{14}$ All of our inferences are based on models estimated on multiply-imputed (MI) datasets. We used the method of multivariate imputation by chained equations (Van Buuren and Groothuis-Oudshoorn 2011), using the outcome variable and all right-hand side covariates at the individual level as predictors of missing values. We combine estimates from MI datasets using Rubin's rule (Rubin 1987). Descriptive statistics for listwise-deleted and multiply-imputed datasets are in the online appendix, along with alternative models based on listwise-deleted data.

${ }^{15}$ Our economic indicators are from the Penn World Tables (Heston, Summers and Aten, 2011) (GDP per capita), World Bank's World Development Indicators (GDP per capita growth through 2012 and unemployment through 2011), the IMF-World Economic Outlook (unemployment through 2012), the Economic Council on Latin America (unemployment through 2012), and the Inter-American Development Bank (inflation through 2012). Please note that unemployment rates for 2012 are based on estimates from the IMF and the ECLA. In simpler preliminary models we used contemporaneous values of inflation, unemployment, and growth; in the models we report we use averages of these figures including the year in which the survey is administered and the immediately-preceding year.
} 
in Honduras 2008 and Dominican Republic 2005, respectively). ${ }^{16}$ At the same time, we cannot exaggerate the extent of variation in economic circumstances during this period. After all, Figure 3 shows that there are tightly coupled co-movements in the series, especially around the period of global recession in 2008-2009 when a trough in economic growth coincided with a peak in inflation and unemployment across countries. Equally important, the paths of economic growth across countries tend to correlate; to wit, the paths of unemployment in Argentina, Peru, and Mexico in Figure 3 tend to stay close to the regional unemployment average. With 83 surveys, however, we anticipate that these correlated series will still furnish enough information to estimate the effects of macro-economic variables with some precision.

\section{Modeling causal heterogeneity across surveys}

Our research strategy calls for the analysis of the impact of corruption victimization on presidential approval; our conjecture is, however, that these effects are conditional on country-level economic performance. In this section, we employ multilevel specifications (i) that appropriately capture the varying impact of country-level covariates on individual-level attitudes toward corruption and government and (ii) that prevent overconfidence in estimates of uncertainty (i.e., we avoid fictitiously narrow standard errors on country-level covariates). The factors that arguably impinge on the effect of corruption victimization on presidential approval vary at both the individual and survey (country-year) levels. The strategy that optimally exploits this information structure is estimation of a partially-pooling model where observations at the individual level are nested within surveys (Gelman et al., 2004; Raudenbush and Bryk, 2002; Steenbergen and Jones, 2002).

We start with an appropriate specification for the observed ordered categories of presidential approval, our outcome indicator (approval ${ }_{r s}$ is the approval response of respondent $r$ in survey $s)$. We assume that a latent continuous variable $y_{r s}^{*}$ in combination with a set of cutpoints $\tau_{s j}$ determines whether the respondent will choose category $j$ (where $j$ is one of five categories from

\footnotetext{
${ }^{16}$ We need to clarify that unemployment rates in Latin America refer for the most part to the urban "formal" sector of the economy, which excludes a proportion of the self-employed economically-active population that does not directly pay taxes or receive transfers from the state. The size of the "informal sector" varies across countries, and we have not found a good way of proxying for this varying size. We use these figures because we think they provide visible signals of how tight labor markets, formal or informal, might be at any given point in time.
} 


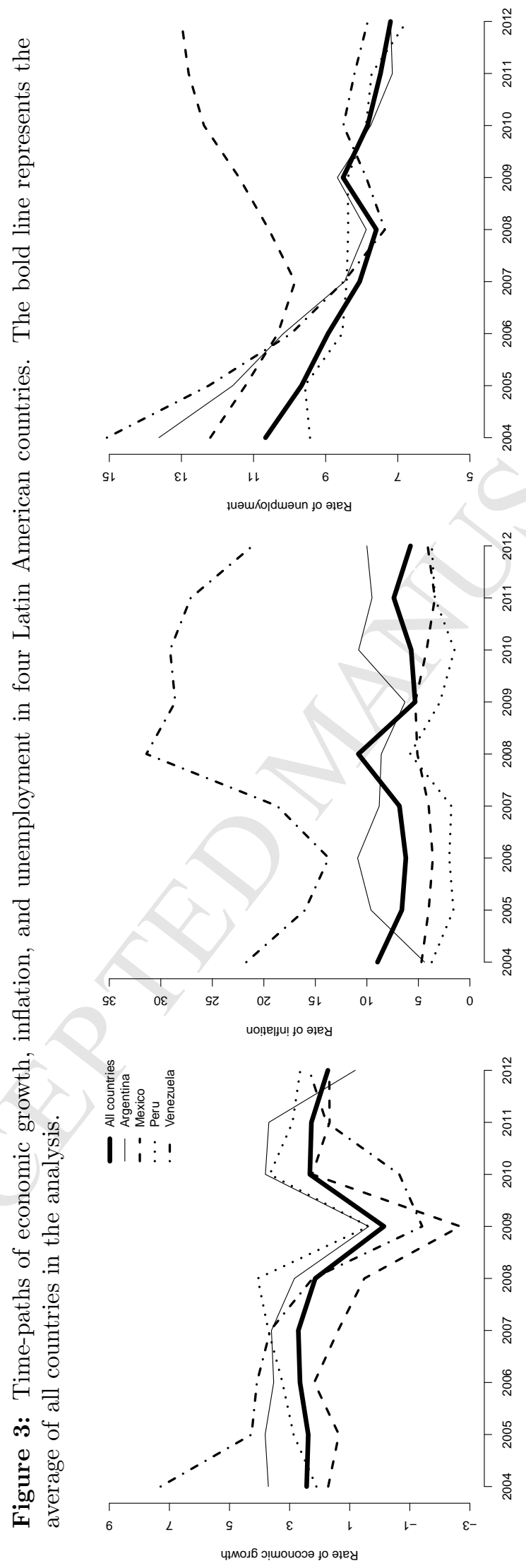


"very bad" to "very good"), as shown in Equation 1:

$$
\text { approval }_{r s}= \begin{cases}\text { very bad } & \text { if } \quad y_{r s}^{*} \leq \tau_{1 s} \\ \text { bad } & \text { if } \tau_{1 s}<y_{r s}^{*} \leq \tau_{2 s} \\ \text { average } & \text { if } \tau_{2 s}<y_{r s}^{*} \leq \tau_{3 s} \\ \text { good } & \text { if } \tau_{3 s}<y_{r s}^{*} \leq \tau_{4 s} \\ \text { very good } & \text { if } \tau_{4 s}<y_{r s}^{*}\end{cases}
$$

The survey-specific cutpoints $\tau_{s j}$ capture the notion that individuals with similar characteristics (i.e., identical values of individual-level variables) may nonetheless evaluate presidents differently in different surveys. In other words, the cutpoints "soak up" the effect on presidential approval of survey-specific factors that are not explicitly controlled in the model, such as the amount of time that the president has been in power.

The second step links the latent variable $y_{r s}^{*}$ to a series of individual-level covariates, as shown in Equation 2:

$$
y_{r s}^{*}=\alpha_{s}+\delta_{s} \cdot \text { corruption victimization }{ }_{r s}+\mathbf{X}_{r s} \boldsymbol{\beta}_{s}+\mathbf{Z}_{r s} \boldsymbol{\gamma}
$$

Equation 2 differs from more conventional descriptions of ordered probit models in including a survey-specific intercept $\alpha_{s}{ }^{17}$ Covariates $\mathbf{X}_{r s}$ observed at the individual level have unmodeled random coefficients $\boldsymbol{\beta}_{s}$ that vary across surveys, whereas covariates $\mathbf{Z}_{r s}$, also observed at the individual level, have fixed coefficients $\gamma$. To determine whether individual-level covariates should be modeled with random or fixed parameters (i.e., whether they belong in $\mathbf{X}$ or $\mathbf{Z}$ ), we first considered variation in the unpooled coefficient estimates of each individual level covariate (much as we do in Figure 2a for the unpooled coefficient estimates of corruption victimization). After determining that there was only minimal cross-survey variation in some of the unpooled coefficients, we substituted them for fixed effects in the final model specifications. Covariates with fixed effects include education, age, gender, and urban/rural environment. Covariates with random effects include a respondent's

\footnotetext{
${ }^{17}$ Note that to achieve identification, we add a sum-to-constant constraint on the four survey-specific $\tau_{s j}$ parameters. We do this by imposing a prior distribution on $\tau_{s j}$ by which these parameters are "centered" around each $\alpha_{s}$, but with wide a priori variance. The result is that the cutpoints are entirely identified by the numbers of individuals within each country that fall within the five different response categories, and not by information from the survey-level covariates.
} 
previous vote choice (anti-incumbent or pro-incumbent, with abstention as the baseline category), left-right self-placement, and income.

The multilevel setup is essential to test our hypotheses, since these concern the capacity of inflation, unemployment, and growth to predict the magnitude of random coefficients $\delta_{s}$ in Equation 2. These coefficients measure the effect of corruption victimization on an individual's latent propensity to approve of the government. We make coefficients $\delta_{s}$ and intercepts $\alpha_{s}$ a function of survey-level economic conditions $\mathbf{E}$ and control covariates $\mathbf{W}$, as seen in Equations 3 and 4 .

$$
\begin{array}{r}
\delta_{s}=\theta_{0}+\mathbf{E}_{s} \boldsymbol{\theta}+\mathbf{W}_{s} \boldsymbol{\lambda}+\sigma_{\delta}^{2} \\
\alpha_{s}=\zeta_{0}+\mathbf{E}_{s} \boldsymbol{\zeta}+\mathbf{W}_{s} \boldsymbol{\mu}+\sigma_{\alpha}^{2}
\end{array}
$$

Our hypotheses about trade-off effects require us to consider parameters $\boldsymbol{\theta}$ intently; these parameters capture how the effects of corruption victimization vary under different values of growth, unemployment, and inflation. Negative effects of inflation and unemployment $(\theta<0)$ and positive effects of growth $(\theta>0)$ would be consistent with a trade-off logic. ${ }^{18}$

\footnotetext{
${ }^{18}$ We estimate the effect of individual- and survey-level covariates on presidential approval in a framework of "modeled varying intercept, modeled varying slopes" (Gelman and Hill 2007). The "random effects" specification takes advantage of within-survey and cross-survey variation to estimate the conditional impact of corruption on approval, but may suffer from "heterogeneity bias." To eliminate such bias, we follow Mundlak's advice of including survey-specific means of individual-level covariates - i.e., W-at the survey-level (Mundlak 1978, Bell and Jones 2012). We estimate the model in a Bayesian framework, since this framework guarantees full propagation of estimation uncertainty into all parameters. Moreover, Bayesian estimates of uncertainty tend to be more conservative than ML estimates (Raudenbush and Bryk (2002, ch. 13); Stegmueller (2013)). We stipulate conjugate uninformative multivariate normal distributions for parameters $\theta, \zeta, \alpha, \beta, \gamma$, and $\tau$, and uniform distributions on the range [0,50] for $\sigma_{\alpha}^{2}$ and $\sigma_{\delta}^{2}$. Ten Markov chains were run for each model for five multiply-imputed datasets (that is, two chains of about $20 \mathrm{~K}$ iterations thinned every tenth scan for each imputed dataset; see fn. 14). We explored posterior distributions graphically and statistically (using Gelman-Rubin's $\hat{R}$ statistic) for evidence of non-convergence. The online appendix contains the Jags code for this model.
} 
Table 1: Multilevel ordered probit models of presidential approval. Estimates are mean and standard deviation of parameter posterior distributions. Models predict $50.3 \%$ of individual responses; the proportional reduction of error statistic for these models is about 0.12 (see fn. 19). Fixed effects estimates are: $0.02 \pm 0.01$ for education, $-0.01 \pm 0.01$ for age and gender, and $0.026 \pm 0.01$ for urban.

\begin{tabular}{|c|c|c|c|c|c|c|}
\hline \multirow[b]{2}{*}{ Parameter } & \multicolumn{2}{|c|}{ Model 1} & \multicolumn{2}{|c|}{ Model 2} & \multicolumn{2}{|c|}{ Model 3} \\
\hline & Mean & SD & Mean & SD & Mean & SD \\
\hline \multicolumn{7}{|c|}{ Predictors of corruption random effect $(\theta$ and $\lambda)$} \\
\hline Intercept & -0.076 & 0.009 & -0.076 & 0.009 & -0.076 & 0.010 \\
\hline GDP & -0.007 & 0.015 & -0.008 & 0.015 & -0.009 & 0.016 \\
\hline Unemployment & & & & & -0.021 & 0.012 \\
\hline Inflation & -0.015 & 0.009 & & & -0.020 & 0.010 \\
\hline Misery & & & -0.023 & 0.011 & & \\
\hline Growth & & & & & -0.002 & 0.010 \\
\hline Corruption (mean) & 0.023 & 0.009 & 0.026 & 0.009 & 0.029 & 0.010 \\
\hline Antincumbent (mean) & -0.022 & 0.010 & -0.022 & 0.010 & -0.022 & 0.010 \\
\hline Proincumbent (mean) & -0.004 & 0.010 & -0.004 & 0.010 & -0.004 & 0.010 \\
\hline Ideology (mean) & 0.000 & 0.010 & 0.005 & 0.010 & 0.009 & 0.012 \\
\hline Income (mean) & -0.009 & 0.010 & -0.010 & 0.010 & -0.011 & 0.011 \\
\hline Education (mean) & 0.015 & 0.013 & 0.011 & 0.013 & 0.012 & 0.014 \\
\hline Age (mean) & -0.013 & 0.015 & -0.013 & 0.015 & -0.012 & 0.015 \\
\hline Women (mean) & 0.022 & 0.011 & 0.022 & 0.011 & 0.022 & 0.011 \\
\hline Urban (mean) & -0.008 & 0.016 & -0.019 & 0.016 & -0.024 & 0.018 \\
\hline$\sigma_{\delta}^{2}$ & 0.053 & 0.009 & 0.051 & 0.010 & 0.054 & 0.009 \\
\hline \multicolumn{7}{|c|}{ Predictors of random intercept $(\zeta$ and $\mu)$} \\
\hline Intercept & 0.328 & 0.064 & 0.328 & 0.065 & 0.328 & 0.063 \\
\hline GDP & -0.067 & 0.120 & -0.084 & 0.121 & -0.102 & 0.115 \\
\hline Unemployment & & & & & -0.012 & 0.088 \\
\hline Inflation & -0.165 & 0.068 & & & -0.162 & 0.070 \\
\hline Misery & & & -0.176 & 0.077 & & \\
\hline Growth & & & & & -0.147 & 0.068 \\
\hline Corruption (mean) & -0.035 & 0.078 & -0.008 & 0.078 & -0.048 & 0.082 \\
\hline Antincumbent (mean) & -0.293 & 0.079 & -0.301 & 0.076 & -0.273 & 0.075 \\
\hline Proincumbent (mean) & 0.231 & 0.073 & 0.227 & 0.073 & 0.225 & 0.071 \\
\hline Ideology (mean) & 0.059 & 0.074 & 0.104 & 0.073 & 0.086 & 0.080 \\
\hline Income (mean) & -0.036 & 0.073 & -0.051 & 0.074 & -0.029 & 0.073 \\
\hline Education (mean) & -0.071 & 0.092 & -0.082 & 0.094 & -0.030 & 0.097 \\
\hline Age (mean) & 0.092 & 0.109 & 0.108 & 0.107 & 0.115 & 0.106 \\
\hline Women (mean) & -0.097 & 0.081 & -0.104 & 0.081 & -0.114 & 0.080 \\
\hline Urban (mean) & -0.188 & 0.113 & -0.252 & 0.124 & -0.214 & 0.131 \\
\hline$\sigma_{\alpha}^{2}$ & 0.580 & 0.051 & 0.579 & 0.051 & 0.566 & 0.052 \\
\hline \multicolumn{7}{|l|}{ Random effects $(\beta)$} \\
\hline Anti-incumbent & -0.228 & 0.022 & -0.228 & 0.023 & -0.228 & 0.023 \\
\hline Pro-incumbent & 0.384 & 0.024 & 0.385 & 0.024 & 0.384 & 0.024 \\
\hline Ideology (L1) & 0.063 & 0.030 & 0.062 & 0.030 & 0.062 & 0.030 \\
\hline Income (Q10) & 0.024 & 0.017 & 0.023 & 0.018 & 0.024 & 0.017 \\
\hline \multicolumn{7}{|c|}{ Survey-level variance parameters } \\
\hline Anti-incumbent & 0.192 & 0.017 & 0.193 & 0.017 & 0.192 & 0.017 \\
\hline Pro-incumbent & 0.208 & 0.018 & 0.208 & 0.018 & 0.208 & 0.018 \\
\hline Ideology (L1) & 0.266 & 0.022 & 0.266 & 0.022 & 0.266 & 0.022 \\
\hline Income (Q10) & 0.141 & 0.014 & 0.141 & 0.014 & 0.141 & 0.014 \\
\hline
\end{tabular}




\section{Results}

Table 1 presents summary results of three models based on different combinations of macroeconomic indicators. Because estimation of Bayesian models based on such a large amount of data is extremely time-intensive, we selected combinations of macroeconomic indicators that we expected to be good predictors of the "corruption effect."

The models in Table 1 reveal interesting patterns about how Latin American citizens with different socio-economic and ideological characteristics evaluate their presidents under varying economic circumstances. Though a full evaluation of all ancillary results is beyond the scope of this paper, the accompanying online appendix includes a variety of graphical summaries of these patterns. In this section, we focus exclusively on how corruption victimization affects respondents' views of the government. More importantly, we discuss how the effects of corruption on presidential approval vary under different economic conditions. ${ }^{19}$

For this purpose, consider the estimates of the "corruption effect" $\left(\delta_{s}\right)$, which depends on $\boldsymbol{\theta}$ and $\boldsymbol{\lambda}$ (Equation 3). Estimates of these parameters appear in the first few rows of Table 1. The intercept estimate (first row) confirms that the average effect of corruption victimization on presidential approval is negative across surveys $(-0.08 \pm 0.01)$. For example, Model 1 suggests that at mean levels of all survey-level controls, a corruption victim will decrease her average propensity to approve

\footnotetext{
${ }^{19}$ We address issues of model fit in several ways. First, we estimated simpler models without random countryspecific cutpoints and/or random covariate effects on much smaller training samples. The deviance statistic for our complete models (around 11,240) suggested a much-improved fit over simpler models including random cutpoints $(12,328)$, which in turn improved markedly over models with completely-pooled cutpoints (13,380). Second, by allowing partially-pooled cutpoints we obtain a very good fit, at the aggregate level, between predicted frequency of responses to presidential approval and observed frequencies. For example, predicted frequencies for the five presidential approval responses based on Model 1 are 0.056, 0.121, 0.440, 0.310, and 0.073, compared to observed frequencies of 0.057, 0.120, 0.439, 0.311, and 0.074. Third, we report a proportion of correct predictions in each model (\% correct). For each observation, the predicted value of presidential approval is the category with largest predicted probability, and the proportion of correct predictions simply tallies how often this predicted value coincides with the observed value. Fourth, because the modal response ("average" presidential approval) is selected quite often, we also present a proportional reduction of error statistic that conveys improvement of our predictions over a demanding baseline that uses the modal response to predict all values. The naïve prediction that all respondents will assess the president as average would be correct about $44 \%$ of the time. Our models improve on this demanding baseline, as suggested by proportional reduction of error statistics that hover around 0.12 .
} 
Figure 4: Predictors of the effect of corruption victimization on presidential approval. Estimates are $80 \%$ and $95 \%$ credible intervals based on the posterior distribution of parameters in Model 3 .

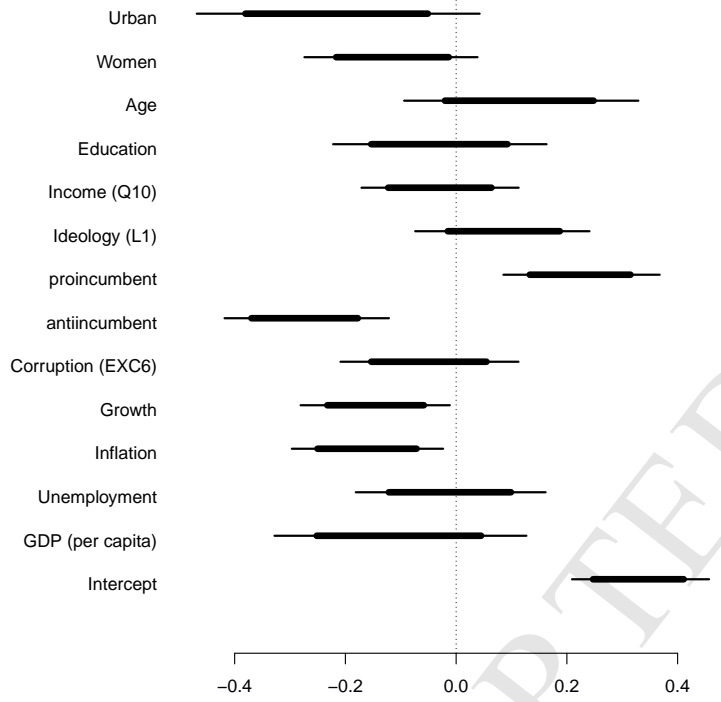

(a) Random intercept predictors $(\zeta, \mu)$

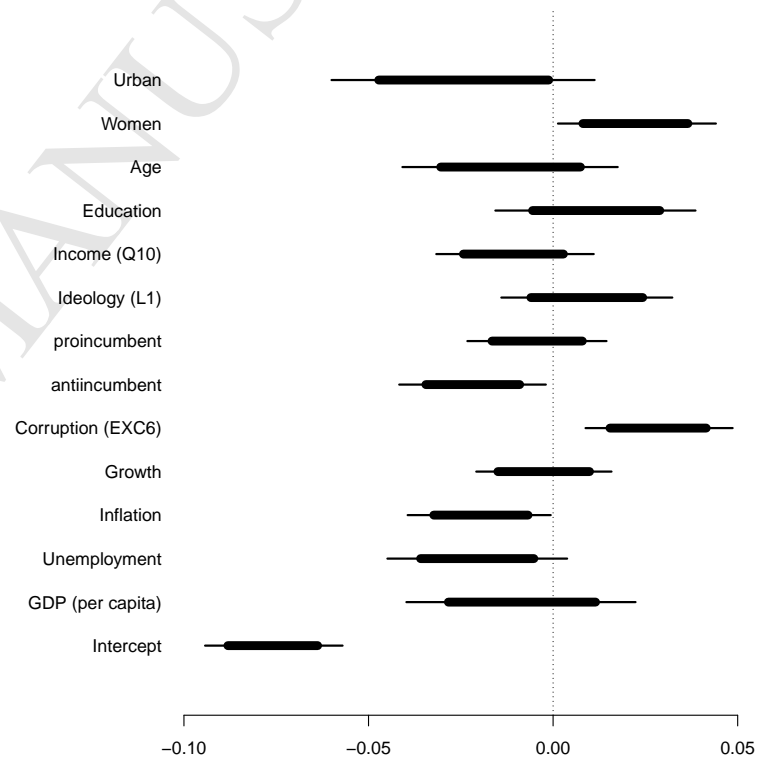

(b) Random coefficient pred. $(\theta, \lambda)$ 
of the government ( $y^{*}$ in Equation 2) by about 0.31 - to gauge the relative size of this impact, consider that the standard deviation of estimated latent propensities hovers around $0.6 .^{20}$ The heterogeneous effect of corruption victimization we had observed in Figure 2a is still conspicuous in the partially-pooled model, as witnessed by the estimates of the corruption victimization effect shown in Figure 2b (these estimates are from Model 1). Compared to the unpooled estimates of Figure 2a, the partially-pooled estimates suggest that a "corruption effect" exists in a larger number of surveys. The estimate of $\sigma_{\delta}^{2}(=0.05 \pm 0.01)$ captures variation in the partially-pooled effects.

We have established that individuals that experience corruption are prone to have more negative views of the government, but also that the size of this effect varies across surveys. The question now is whether cross-survey variation in the size of these effects is driven by economic factorsinflation, unemployment, growth - after controlling for survey-level confounders. We provide in Figure 4 a graphical representation of the effects of all survey-level covariates on random intercepts and random coefficients (these estimates are all from Model 3). Recall that coefficient estimates in Figure 4a capture the direct effect of survey-level indicators on presidential approval, whereas the estimates in Figure 4b relay the impact of survey-level indicators on the "corruption effect." For example, respondents that voted pro-incumbent are more likely to approve of the president (the estimate of pro-incumbent in Figure 4a is positive and bounded away from zero), but they are neither more nor less likely to disapprove of the president if they are corruption victims (the corresponding estimate in Figure $4 \mathrm{~b}$ straddles zero).

We focus on Model 3 to comment on the estimated effects of inflation, unemployment, and growth. The picture that emerges for inflation is in principle consistent with the trade-off hypothesis: as can be seen in Figure 4b, the $95 \%$ credible interval for the inflation coefficient is negative. This estimate implies that citizens that have experienced corruption at the hands of bureaucrats are more likely to award worse grades to their presidents under conditions of high inflation than under conditions of price stability. Alternatively, Latin American citizens tend to be more forgiving

\footnotetext{
${ }^{20}$ All covariates at both individual and survey levels are standardized. The average negative effect in Figure $2 \mathrm{~b}$ appears to be larger $(-0.08$ vs -0.05$)$ than the complete-pooling estimate depicted by the gray bar in Figure $2 \mathrm{a}$, but consider that the partially-pooling estimate is based on a model that appropriately captures the ordered-categorical nature of the outcome variable.
} 
of corruption as long as the government maintains a stable macroeconomic environment.

To build a better intuition for the substantive magnitude of this effect, the first plot in Figure 5 displays the expected impact of inflation (log scale) on the corruption effect, laid over the distribution of partially-pooled survey-specific effects. ${ }^{21}$ We confirm that in countries undergoing processes of high inflation, respondents that experience corruption are much more likely to express disapproval of the president than in countries with monetary stability. We hasten to add that this estimated effect obtains after controlling for survey-level and individual-level confounders. For example, compare a citizen that has experienced bureaucratic bribery in two different countries, one with a low inflation rate $(2.7 \%$, which corresponds to 1 in the log scale, as in Panama 2006), and one with a severe inflationary problem (20.1\%, about 3 in the log scale, as in Venezuela 2008). The expected change in the underlying propensity to approve government performance would then be about $0.09( \pm 0.05)$, or about two-fifths of the standard deviation of corruption effects across surveys $\left(\sigma_{\delta}=0.23\right)$ and slightly more than one-tenth of the standard deviation of the latent propensity to approve the president $\left(\mathrm{SD}\left(\hat{y}^{*}\right)=0.6\right)$. We would not characterize this latter effect as colossal, but it definitely leads to conspicuous shifts in the president's approval numbers. ${ }^{22}$

The point estimate of the effect of unemployment in Model 3 is also negative, but the $95 \%$ credible interval for this parameter straddles zero. To place this result in perspective, consider unemployment rates in El Salvador 2012 (5.7\%) and Colombia 2008 (11.3\%), which roughly correspond to the $25^{\text {th }}$ and $75^{\text {th }}$ sample percentiles. The propensity of an average respondent to disapprove of the president would be about $0.04 \pm 0.025$ lower in Colombia than in El Salvador. This is a relatively small effect (a bit over one-twentieth of the standard deviation of $y^{*}$ ) and is estimated less precisely. We also consider the possibility that the high rates of both inflation and unemployment drive the corruption effect downwards. To test this proposition, we substitute Okun's misery index for inflation and unemployment in Model 2. The misery index is simply the

\footnotetext{
${ }^{21}$ To build these plots, we sample directly from the joint posterior distribution of parameters, thus appropriately accounting for uncertainty in, and patterns of correlation among, coefficient estimates. All other variables are held at mean sample values.

${ }^{22}$ This indirect effect of inflation on presidential approval is complemented by the direct effect displayed in Figure 4a. Regardless of whether they are corruption victims or not, citizens of countries with high inflation rates are more likely to disapprove of the president than citizens in countries with low inflation rates.
} 
Figure 5: Predictors of the effect of corruption victimization on presidential approval conditional on inflation and unemployment. Estimates are medians and $95 \%$ credible intervals of marginal effects form Model 3. Predictors are standardized.
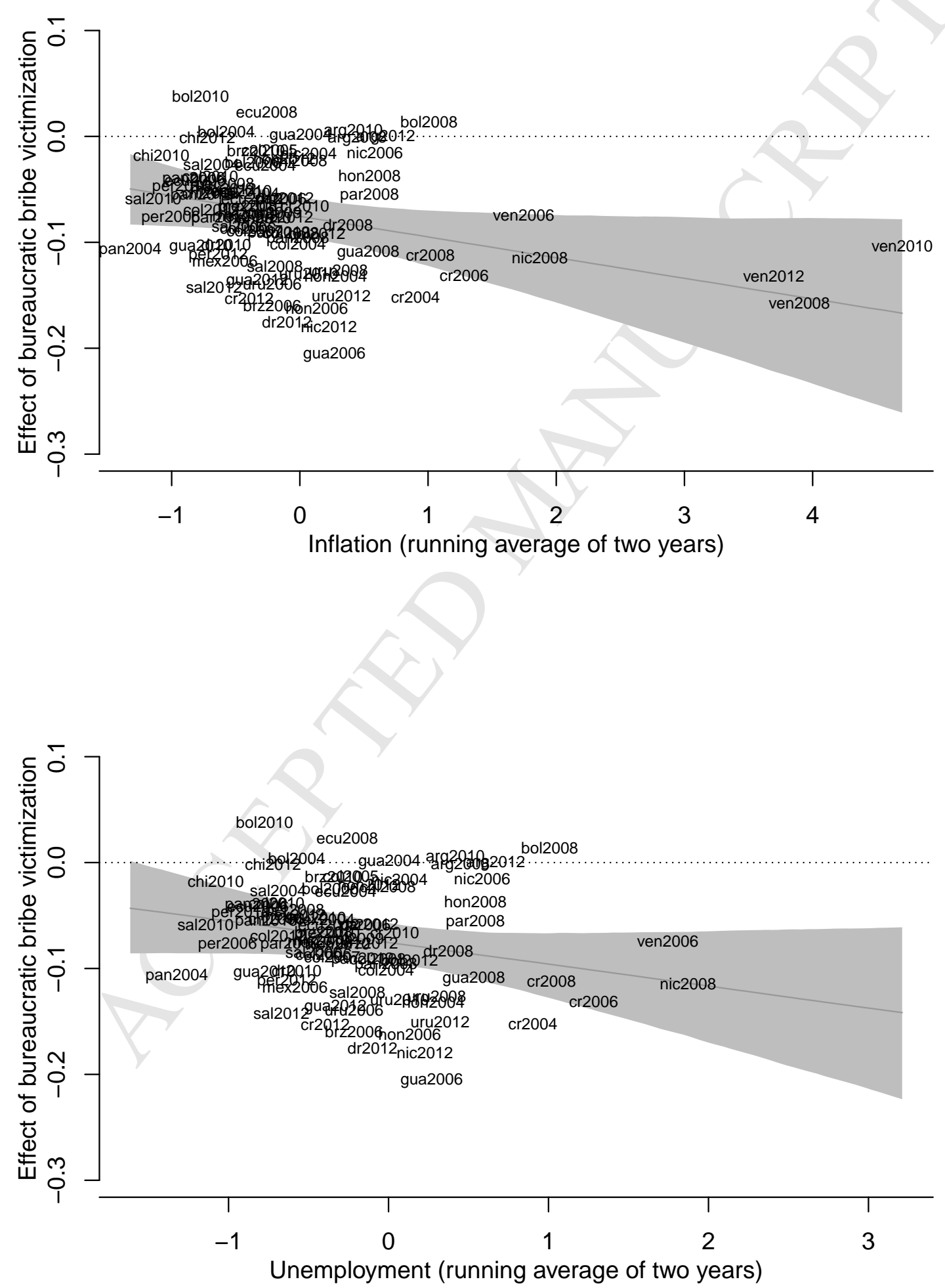
sum of the rates of inflation and unemployment for each of our observations. As can be seen in Table 1, combining inflation and unemployment into a single misery index yields larger estimates of the effects of macroeconomic conditions. The direct effect of misery on presidential approval is $-0.176 \pm 0.08$, and the effect of misery on the corruption effect is $-0.023 \pm 0.011$. This effect is slightly larger than the inflation effect detected in Model 3.

Venezuela's inflation rate over the period 2006-2010 is higher than the recent modal experience in Latin America, as can be gleaned from Figure 5. ${ }^{23}$ One concern is that Venezuela's observations may be outliers that drive the impact of economic outcomes on the corruption effect. In general, Venezuela's observations are not particularly leveraged. In fact, when we consider the values of survey-level indicators, only Venezuela 2010 among the four observations from that country has a high degree of leverage; three other observations (Brazil 2012, Chile 2012, and Guatemala 2004) have similarly large degrees of leverage. ${ }^{24}$

Be this as it may, we have re-estimated Models 2 and 3 on a sample that excludes all Venezuelan surveys, not just the one with high leverage. Table 2 displays these new estimates of the effects of inflation, unemployment, growth, and misery on the size of the corruption effect. Excluding observations from Venezuela has an impact on uncertainty intervals: standard deviations are somewhat larger for these new estimates, increasing from around 0.01 to about 0.013 . More problematically, the estimates of the impact of inflation and misery now suggest no impact on the corruption effect. ${ }^{25}$ In contrast, the posterior density of the unemployment coefficient based on the smaller sample is basically identical to the one we estimate on the full sample: the estimate is negative, but not reliable enough that it excludes zero.

The exclusion of all observations from Venezuela eliminates the impact of inflation on the cor-

\footnotetext{
${ }^{23}$ Inflation rates are also arguably higher in Argentina, but the official reports of inflation on which we base our analysis paper over this reality (see, inter alia, "Argentina's inflation problem", The Economist, February 25, 2012).

${ }^{24}$ The hat values for these four observations (around 0.34 ) are more than twice as large as the mean hat value in the sample $(\bar{h} \approx 0.15)$.

${ }^{25}$ Maximum-likelihood estimates of these quantities confirm that inflation is not a statistically significant predictor of the corruption effect when we exclude Venezuela, but the estimate of misery remains negative and significant at the $90 \%$ confidence level. Part of the explanation for this discrepancy lies in the fact that ML estimates of uncertainty in multilevel models tend to be optimistic, whereas the Bayesian estimates we use here are appropriately conservative (Stegmueller, 2013).
} 
Table 2: Coefficients correspond to estimates of the impact of economic factors on the corruption effect, based on a sample that excludes all Venezuelan surveys.

\begin{tabular}{lcccc}
\hline & \multicolumn{2}{c}{ Model 2 } & \multicolumn{2}{c}{ Model 3 } \\
Parameter & Mean & SD & Mean & SD \\
\hline Misery & -0.01 & 0.011 & & \\
Inflation & & & -0.003 & 0.013 \\
Unemployment & & & -0.018 & 0.013 \\
Growth & & & -0.003 & 0.011 \\
\hline
\end{tabular}

ruption effect. How should one then interpret the contribution of Venezuela to these estimates? We think the answer hinges on two related questions: First, should all Venezuelan observations be dropped, or only those with high leverage? We have opted to eliminate all Venezuela observations, but a more consistent and principled decision rule would have been to eliminate the four observations, only one of which came from Venezuela, with high leverage. Second, we note that though Venezuela's inflationary experience over the past few years has been dismal, this is hardly a reason to exclude Venezuela from our models. We do not know of any theoretical reasons to expect that citizens of other Latin American countries would have behaved any differently than Venezuelans, had they experienced similar high rates of inflation. This is not to deny the uniqueness of Venezuela's development over the last decade, but to justify removal one would need to elaborate a theory of why inflation matters exclusively under the set of conditions that characterize Venezuela and not anywhere else. Our own view is that information provided by the Venezuelan observations should be, at worst, only mildly discounted. In the end, however, the reader should reach her own conclusions on whether all observations should be weighted equally or whether Venezuela should be discounted entirely.

Back to the full sample, we find essentially no impact of economic growth on the corruption effect, which is inconsistent with the economic performance trade-off hypothesis. We only enter growth as a predictor in Model 3, where we also control for unemployment and inflation; in this sense, it bears remembering that the estimate we recover is of the partial effect of growth on presidential approval after accounting for the effects of inflation and unemployment, which are likely to mediate the effect of growth on presidential approval. In thinking about the effects of growth, inflation, and unemployment, consider as well that our models control for level of economic development (GDP per capita) based on the argument that more developed countries might enjoy an "approval premium", might be more effective in limiting corruption, and may also be able 
to generate better economic outcomes. However, we do not find evidence consistent with this argument. Basically, level of economic development has no discernible impact on our estimates of the corruption effect.

We comment finally on whether the magnitude of the corruption effect on presidential approval is conditional on the level of corruption in the country. That is, we want to understand whether a respondent that experiences corruption displays the same propensity to blame the government regardless of the incidence of bribery. To this effect, our models include within-survey means of corruption victimization as predictors in the survey-level models. These variables are included to eliminate the risk of heterogeneity bias (see fn. 18), but their coefficients have a useful interpretation. For example, as the number of corruption victims increases in a country, the negative effect of corruption victimization on presidential approval becomes slightly less pronounced (the estimate is $0.03 \pm 0.01$ in Model 3). One interpretation of this finding is that citizens become inured to acts of corruption in countries with high levels of corruption victimization, so that they do not even bother to let personal experiences of bureaucratic corruption affect their approval of the president for better or worse. By the same token, respondents in relatively clean countries would be quick to lambast the government for the occasional bribery mishap. If this interpretation were correct, we would conclude that a virtuous circle of sorts obtains in Latin America: In countries with relatively low corruption, citizens that experience corruption are much less likely to "let it go." However, this good governance effect (0.03) is too small to be of substantive importance.

\section{Conclusion}

We have tested in this paper one version of the trade-off hypothesis that postulates that citizens are less likely to punish governments that condone or engage in corruption as long as they deliver good economic results. We have focused on Latin America using a multi-level analysis based on a much larger amount of survey data than in previous studies and using an estimation strategy, Bayesian inference, that recovers appropriately conservative estimates of uncertainty. We contended at the outset that the way previous works have measured corruption perceptions, often based upon limited public opinion data sets, may have led to exaggerated and idiosyncratic assessments of the impact of economic performance on what we call the "corruption effect." In particular, we were suspicious 
of analyses that suggest that Latin American voters support leaders that condone corruption as long as they deliver good economic outcomes. We find that when it comes to presidential approval, Latin American voters in recent years have not behaved as uninformed, easily-duped citizens. Instead, those who experience corruption are always more likely to offer negative assessments of the president's ability. We believe that our main findings constitute an important contribution to the current scholarly debate, since they attenuate the more pessimistic conclusions of works that find evidence for a strong version of the trade-off hypothesis.

Having said that, we find some evidence in favor of a weaker version of the trade-off hypothesis: those that suffer corruption and find themselves in a situation of poor economic performance are even more likely to offer pessimistic assessments of the sitting president. This is especially true when governments are unable to guarantee a stable macroeconomic environment or employment opportunities. However, the magnitude and reliability of this effect depends heavily on the inclusion of information from Venezuela, which has much higher than average inflation during the period under inspection. We have to admit that different individuals will weigh this evidence differently, depending on whether they feel that Venezuelan observations should be discounted entirely. Our view is that they should not be discounted at all, as we know no economic theory that suggests that individuals react differently to inflation across national contexts. In any case, let us emphasize that citizens that suffer corruption do not give presidents a free pass as long as they preserve price stability. We find that experiences of corruption lead to presidential disapproval even in settings with very low inflation. We also underscore that, against expectations based on the trade-off hypotheses, economic growth neither increases nor decreases the effect of corruption on presidential approval. Theoretically, we expected that inflation and unemployment would increase the size of the corruption effect but economic growth would not.

Despite lapses in macroeconomic stability, Latin America has become more affluent and achieved a better distribution of wealth in the past decade (Ferreira et al., 2013). As it continues to do so, it may start to display a pattern of convergence with advanced industrial societies where citizens, once they attained improved economic conditions, began to demand better government and greater accountability from their elected officials. Moreover, unlike the pessimistic views about the entrenchment of corruption noted at the beginning of the paper, the evidence that we uncovered should be good news for both domestic and international actors working toward strategies aimed 
at curbing corruption. If indeed people's evaluations of government are negatively affected by corruption most of the time, and become more negative with worse economic outcomes, it is then possible to capitalize on their malaise by proposing candidates and/or policy initiatives which can alter the status quo. To put it differently, there seems to be a pragmatic constituency out there that would vote for honest and competent political leadership. In and of itself, this is a good sign for those who believe that democratic governance in the region can be much improved in the near future. As Shifter $(2011,120)$ argues, "[i]ncreasingly, the region is behaving politically much like other parts of the world, where standards of performance and effectiveness are decisive in determining electoral choices and outcomes." Based on our findings, perhaps the time has come to update the stereotype of the Latin American voter who supports "corrupt but effective" over "clean but inept" politicians to one that will settle for nothing less than clean and effective governments. 


\section{References}

Abramo, Claudio Weber. 2008. "How Much do Perceptions of Corruption Really Tell Us?" Economics: The Open-Access, Open-Assessment E-Journal 2(3):1-56.

Ades, Alberto and Rafael Di Tella. 1999. "Rents, Competition, and Corruption." American Economic Review 89(4):982-993.

Anderson, Christopher J. 2007. "The End of Economic Voting? Contingency Dilemmas and the Limits of Democratic Accountability." Annual Review of Political Science 10:271-296.

Anderson, Christopher J. and Yuliya V. Tverdova. 2003. "Corruption, Political Allegiances, and Attitudes toward Government in Contemporary Democracies." American Journal of Political Science 47(1):91-109.

Bell, Andrew and Kelvyn Jones. 2012. "Explaining Fixed Effects: Random Effects Modelling of Time-Series Cross-Sectional and Panel Data." Unpublished manuscript, University of Bristol.

Calvo, Ernesto. 2007. "The Responsive Legislature: Public Opinion and Law Making in a Highly Disciplined Legislature.” British Journal of Political Science 37:263-280.

Canache, Damarys and Michael E. Allison. 2005. "Perceptions of Political Corruption in Latin American Democracies." Latin American Politics and Society 47(3):91-111.

Carlin, Ryan E., Gregory J. Love and Cecilia Martínez-Gallardo. forthcoming. "Cushioning the Fall: Scandals, Economic Conditions, and Executive Approval." Political Behavior .

Carlsen, Fredrik. 2000. "Unemployment, Inflation and Government Popularity-Are There Partisan Effects?" Electoral Studies 19(2-3):141-150.

Chang, Eric, Miriam Golden and Seth J. Hill. 2010. "Legislative Malfeasance and Political Accountability." World Politics 62(2):177-220.

Chang, Eric and Yun Han Chu. 2006. "Corruption and Trust: Exceptionalism in Asian Democracies?" Journal of Politics 68:259-271. 
Choi, Eunjung and Jongseok Woo. 2010. "Political Corruption, Economic Performance, and Electoral Outcomes: A Cross-National Analysis." Contemporary Politics 16:249-262.

Davis, Charles L., Roderic A. Camp and Kenneth M. Coleman. 2004. "The Influence of Party Systems on Citizens' Perceptions of Corruption and Electoral Response in Latin America." Comparative Political Studies 37(6):677-703.

Davis, Christina L. 2004. "International Institutions and Issue Linkage: Building Support for Agricultural Trade Liberalization." American Political Science Review 98(1):153-169.

Della Porta, Daniela. 2000. Social Capital, Beliefs in Government, and Political Corruption. In Disaffected Democracies: What's Troubling the Trilateral Countries?, ed. Susan Pharr and Robert Putnam. Princeton University Press.

Echegaray, Fabián. 2005. Economic Crises and Electoral Responses in Latin America. New York: University Press of America.

Erikson, Robert S. 2004. Macro vs. Micro-Level Perspectives on Economic Voting: Is the MicroLevel Evidence Endogenously Induced? Unpublished ms. Columbia University. Prepared for the 2004 Political Methodology Meetings, July 29-31, 2004, Stanford University.

Evans, Geoffrey and Robert Andersen. 2006. "The Political Conditioning of Economic Perceptions." Journal of Politics 68(1):194-207.

Ferraz, Claudio and Frederico Finan. 2008. "Exposing Corrupt Politicians: The Effects of Brazil's Publicly Released Audits on Electoral Outcomes." Quarterly Journal of Economics 123(2):703745.

Ferreira, Francisco H. G., Julian Messina, Jamele Rigolini, Luis-Felipe López-Calva, Maria Ana Lugo and Renos Vakis. 2013. Economic Mobility and the Rise of the Latin American Middle Class. Washington, D.C.: World Bank Publications.

Gelineau, Francois. 2007. "Presidents, Political Context, and Economic Accountability: Evidence from Latin America." Political Research Quarterly 60(3):415-428. 
Gelman, Andrew and Jennifer Hill. 2007. Data Analysis Using Regression and Multilevel/Hierarchical Models. Cambridge, MA: Cambridge University Press.

Gelman, Andrew, John B. Carlin, Hal S. Stern and Donald B. Rubin. 2004. Bayesian Data Analysis. Boca Raton, FL: Chapman \& Hall/CRC Press.

Gingerich, Daniel W. 2009. "Corruption and Political Decay: Evidence from Bolivia." Quarterly Journal of Political Science 4(1):1-34.

Golden, Miriam. 2009. "The Electoral Underpinnings of Corruption in Rich and Poor Democratic Polities." Unpublished ms, UCLA.

Gronke, Paul and Brian Newman. 2003. "FDR to Clinton, Mueller to ?: A Field Essay on Presidential Approval." Political Research Quarterly 56(4):501-512.

Hellwig, Timothy and David J. Samuels. 2007. "Voting in Open Economies: The Electoral Consequences of Globalization." Comparative Political Studies 40:283-306.

Heston, Alan, Robert Summers and Bettina Aten. 2011. Penn World Table Version 7.0. Technical report Center for International Comparisons of Production, Income and Prices at the University of Pennsylvania (CICUP).

Hochstetler, Kathryn. 2006. "Rethinking Presidentialism: Challenges and Presidential Falls in South America." Comparative Politics 38(4):401-418.

Johnson, Gregg B. and Sooh-Rhee Ryu. 2010. "Repudiating or Rewarding Neoliberalism? How Broken Campaign Promises Condition Economic Voting in Latin America." Latin American Politics and Society 52:1-24.

Kayser, Mark A. 2009. "Partisan Waves: International Business Cycles and Electoral Choice." American Journal of Political Science 53(4):950-970.

Kayser, Mark A. and Christopher Wlezien. 2011. "Performance Pressure: Patterns of Partisanship and the Economic Vote." European Journal of Political Research 50:365-394.

Kinder, Donald R. and D. Roderick Kiewiet. 1981. "Sociotropic Politics: The American Case." British Journal of Political Science 11(April):129-161. 
Klaŝnja, Marko, Joshua A. Tucker and Kevin Deegan-Krause. 2012. "Pocketbook vs. Sociotropic Corruption Voting." Unpublished manuscript.

Kurer, Oskar. 1993. "Clientelism, Corruption, and the Allocation of Resources." Public Choice $77(2): 259-273$.

Kurer, Oskar. 2001. Why Do Voters Support Corrupt Politicians? In The Political Economy of Corruption, ed. Arvind K. Jain. London: Routledge.

Lewis-Beck, Michael S. 1988. Economics and Elections: The Major Western Democracies. Ann Arbor, MI: University of Michigan Press.

Lewis-Beck, Michael S. and Mary Stegmaier. 2008. "The Economic Vote in Transitional Democracies." Journal of Elections, Public Opinion and Parties 18(3).

Mauro, Paolo. 1995. "Corruption and Growth." Quarterly Journal of Economics 110(3):681-712.

McCann, James A. and Jorge I. Domínguez. 1998. "Mexicans React to Electoral Fraud and Political Corruption: An Assessment of Public Opinion and Voting Behavior." Electoral Studies 17:483503.

Morris, Stephen D. 2008. "Disaggregating Corruption: A Comparison of Participation and Perceptions in Latin America with a Focus on Mexico." Bulletin of Latin American Research 27(3):388409.

Mundlak, Yair. 1978. "On the Pooling of Time Series and Cross Section Data." Econometrica $46(1): 69-85$.

Palmer, Harvey D. and Raymond M. Duch. 2001. "Do Surveys Provide Representative or Whimsical Assessments of the Economy?" Political Analysis 9(1):58-77.

Pereira, Carlos, Marcus A. Melo and Carlos M. Figueiredo. 2009. "The Corruption-Enhancing Role of Re-Election Incentives? Counterintuitive Evidence from Brazil's Audit Reports." Political Research Quarterly 62.

Pérez Liñán, Aníbal. 2007. Presidential Impeachment and the New Political Instability in Latin America. New York, NY: Cambridge University Press. 
Powell, G. Bingham Jr. and Guy D. Whitten. 1993. "A Cross-National Analysis of Economic Voting: Taking Account of the Political Context." American Journal of Political Science 37:391-414.

Raudenbush, Stephen and Anthony Bryk. 2002. Hierarchical Linear Models: Applications and Data Analysis Methods. Advanced Quantitative Techniques in the Social Sciences second edition ed. Thousand Oaks, CA: Sage Publications.

Remmer, Karen. 2003. Elections and Economics in Contemporary Latin America. In Post-Reform Politics in Latin America: Competition, Transition, Collapse, ed. Carol Wise and Riordan Roett. Washington, DC: Brookings Institution Press.

Rose, Richard and William Mishler. 2007. "The Gap Between Experience and Perception of Corruption." Paper presented at the ECPR General Conference in Pisa, Italy.

Rubin, Donald B. 1987. Multiple Imputation for Nonresponse in Surveys. New York, NY: J. Wiley and Sons.

Rundquist, Barry S., Gerald S. Strom and John. G Peters. 1977. "Corrupt Politicians and Their Electoral Support: Some Experimental Observations." American Political Science Review 71:954-963.

Seligson, Mitchell A. 2002. "The Impact of Corruption on Regime Legitimacy: A Comparative Study of Four Latin American Countries." Journal of Politics 64:408-433.

Seligson, Mitchell A. 2006. "The Measurement and Impact of Corruption Victimisation: Survey Evidence from Latin America." World Development 34(2):381-404.

Shifter, Michael. 2011. "A Surge to The Center." Journal of Democracy 22(1):107-121.

Singer, Matthew. 2013. "Economic Voting in an Era of (Non) Crisis: Economic Voting in Latin America 1982-2010." Comparative Politics 45(2):169-185.

Steenbergen, Marco R and Bradford S. Jones. 2002. "Modeling Multilevel Data Structures." American Journal of Political Science 46:218-237.

Stegmueller, Daniel. 2013. "How Many Countries for Multilevel Modeling? A Comparison of Frequentist and Bayesian Approaches." American Journal of Political Science 57(3):748-761. 
Stokes, Susan C. 2001. Mandates and Democracy: Neoliberalism by Surprise in Latin America. New York, NY: Cambridge University Press.

Tavits, Margit. 2007. "Clarity of Responsibility and Corruption." American Journal of Political Science 51(1):218-229.

Tverdova, Yuliya V. 2011. "See No Evil: Heterogeneity in Public Perceptions of Corruption." Canadian Journal of Political Science 44(1):1-25.

Van Buuren, Stef and Karin Groothuis-Oudshoorn. 2011. "mice: Multivariate Imputation by Chained Equations in R." Journal of Statistical Software 45(3):1-67.

Winters, Matthew S. and Rebecca Weitz-Shapiro. 2013. "Lacking Information or Condoning Corruption? Voter Attitudes Toward Corruption in Brazil." Journal of Comparative Politics $45(4): 418-436$.

Zechmeister, Elizabeth J. and Daniel Zizumbo-Colunga. 2013. "The Varying Political Toll of Concerns about Corruption in Good versus Bad Economic Times." Comparative Political Studies 46(10):1190-1218. 


\section{Highlights}

- We hypothesize that inflation and unemployment drive citizen willingness to pin corruption on the incumbent.

- We test this hypothesis on survey data from eighteen Latin American countries between 2004 and 2012.

- We do not find support for a strong trade-off hypothesis: regardless of economic context, citizens who suffer corruption tend to disapprove of their presidents.

- We find some support for a weak trade-off hypothesis: in contexts of high inflation, those who suffer corruption give even lower approval rate to presidents. 